\title{
MEMBANGUN KEPEMIMPINAN UMKM TERPADU PADA SEKTOR PETERNAKAN
}

\author{
Prayitno \\ Tabrani \\ Maikal Soedijarto \\ Politeknik Trisila Dharam \\ Politeknik Trisila Dharma \\ STIEPARI Semarang \\ pra.yitno.py17@gmail.com \\ tabrani2@yahoo.co.id \\ maikalsoedijarto@gmail.com
}

\begin{abstract}
This research helps leaders to grow and integrate their efforts from one business to several related businesses, using a longitudinal approach to know for sure the development of an object, a survey to collect data from a research sample. This research uses longitudinal design in which qualitative and quantitative techniques are used, using the random purpose sampling technique, the data collection process using the study cohort. The result of the research stated that with strong experience and commitment the UMKM perpetrator is able to develop independent business so as to become the business owner and become the leader in that effort, along with the process of experiencing business constraints but can be solved and generate new businesses that still exist kaitanya with the main business so that the business is combined and mutually supportive. This study also corroborates research by Rajani and Sarada (2008) which shows a strong influence between leadership on the performance of UMKM
\end{abstract}

Keywords: experience, commitment, leadership umkm

\section{PENDAHULUAN}

Usaha Kecil dan Menengah (UKM) memiliki peranan cukup penting dalam perekonomian Indonesia. Namun dalam perkembangannya, UKM masih menghadapi berbagai kendala. sejak tahun 2010 hingga sekarang terdapat enam masalah pokok yang menghalangi UKM untuk menaikkan kelas usahanya. Keenam poin tersebut yakni pengetahuan, pemasaran, permodalan, teknologi, legal maupun administrasi keuangan, dan jaringan ( CEO Pro Indonesia Foundation, 2010). Dalam survei yang dilakukan di 30 kota, UKM mengatakan kendala utama ada di modal ( kontan.co.id). Selain itu pasar menjadi kendala karena banyak pelaku UKM memulai usaha karena terpaksa, bukan diawali dengan apa yang diinginkan konsumen. Hampir $90 \%$ pelaku UKM mulai usahanya by accident bukan by design. Ketidakpahaman hukum terkadang menghambat UKM. Misal ketika satu UKM tumbuh besar namun belum mendaftarkan paten produknya, lalu nama produk diambil orang. Hasil produk UMKM menjadi kendala sebab produksi berdasarkan kemampuan pelaku UMKM bukan berdasarkan pasar sehingga jaringan pemasaran mengalami hambatan.

Data berbeda ditunjukan oleh Kadin, setidaknya ada empat kendala yang dihadapi UMKM, yaitu pembiayaan, teknologi dan inovasi produk, riset pasar dan terakhir inefisiensi (Kadin Jatim, 2013) . Pembiayaan masih menjadi kendala karena sulitnya persyaratan untuk 
mendapatlan kredit perbankan bagi UMKM seperti kelayakan usaha, rekening 3 bulan harus bagus dan keberadaan agunan serta lamanya berbisnis. Fakta di lapangan, banyak pengusaha UMKM yang sebenarnya bisnisnya sangat feasible, namun dinilai tidak bankable hanya karena masalah agunan atau lamanya berbisnis.

Kendala kedua, permasalahan teknologi dan inovasi produk. Permasalahan ini menjadi problem klasik para pengusaha UMKM. Dampaknya, para UMKM kerap kebingungan ketika berhadapan dengan ekspansi produk dari pabrik-pabrik yang lebih besar dan mapan. Jika tidak ada pendekatan teknologi dan penumbuhan budaya inovasi, UMKM cepat atau lambat akan mati. Setidak-tidaknya UMKM akan sulit berkembang besar dan selamanya jadi pemain medioker alias menengah. Padahal, UMKM-UMKM berhadapan dengan bisnis besar yang sangat peka teknologi dan inovasi, sehingga lebih efisien dan lebih bisa mengikuti perubahan di pasar.

Kendala ketiga, riset pasar. Selama ini, UMKM nyaris tak didukung dengan riset pasar yang memadai terkait model promosi, peluang pasar, pesaing, barang substitusi dan komplementer atas produk-produk pengusaha muda, selera konsumen, tren pasar, dan faktor-faktor eksternal lainnya. Kondisi ini membuat ekspansi bisnis UMKM sangat terbatas. Tanpa dukungan riset pasar, sulit bagi pengusaha pemula untuk bisa mengetahui apa yang dibutuhkan pasar.

Kendala keempat, inefisiensi. UMKM belum mempunyai tingkat efisiensi yang optimal karena tidak mampu menciptakan skala ekonomi. Untuk persoalan ini, harus adanya klasterisasi UMKM (kadin jatim) . Pengembangan UMKM harus bertumpu pada karakteristik lokal (economies of localization) dan berbasis pada kebijakan pemberdayaan masyarakat lokal (endogenous development policies). Artinya, pengembangan UMKM didasarkan pada pemanfaatan potensi sumberdaya manusia lokal, sumberdaya institusional lokal, sumberdaya fisik lokal, dan sumberdaya alam yang dimiliki daerah. Pendekatan ini memberi titik tekan pada pemberian prakarsa lokal (local initiatives) untuk menstimulasi pertumbuhan ekonomi di tingkat lokal guna membuka lapangan pekerjaan baru dan meningkatkan daya saing ekonomi masyarakat.

Dapat diambil kesimpulan dari kedua data diatas adalah bahwa permasalahan utama yang dihadapi UMKM yang hinggga sekarang belum ada penyelesaian adalah pengetahuan, (Dalkir, 2005). Pengetahuan yang dimaksud adalah merujuk pada pengalaman yang dimiliki oleh pemilik usaha UMKM. Sebab indikator dari kedua data yang ditampilkan dapat terpenuhi seiring perkembangan teknologi dan perbankan namun permasalahan kemepimpinan menjadi permasalahan utama bagi UMKM sekarang ini.

Kepemimpinan dalam sebuah usaha kecil dan menengah permasalahan menjadi semakin komplek sebab pemilik usaha sekaligus menjadi seorang pemimpin sehingga apa yang dilakukan oleh seorang pemimpin juga menjadi kebijakan usaha itu, tidak adanya kontrol pembanding bahwa kebijakan itu salah atau benar namun, Karyawan yang diberdayakan atas dasar suka dan tidak suka, kreativitas karyawan sulit untuk berkembang, disisi lain memiliki kekuatan sebab rantai kebijakan tidak panjang, semua kegiatan tidak perlu menunggu keputusan yang diatasanya lagi. Seorang pemimpin usaha kecil menengah memiliki persepsi sendiri dalam memimpin usahanya berdasarkan pengalaman puluhan tahun yang tak dipelajarai dalam lingkungan pendidikan formal sebab rata - rata pemilik sekaligus pemimpin dalam usaha kecil dan menengah tidak memiliki pendidikan formal yang cukup memadai namun sebenarnya tidakan yang mereka lakukan dalam menjalankan usahanya sebenarnya secara akademis ada teorinya tetapi tidak diketahui. Ada tujuh konsep kepemimpinan, dalam studi manajemen pengetahuan, yaitu: konteks, kompetensi, 
budaya, komunitas, percakapan dan bahasa umum, komunikasi, pembinaan (Crăc pengetahuan iun, Năstase, Stamule, \& Vizitiu, 2015).

Peran pengalaman dan pengetahuan seorang pemilik sekaligus pemimpin dalam UMKM sangat menentukan maju dan mundurnya sebuah usaha, bila pengalaman semakin banyak dan pengetahuanya akan sebuah usaha baik maka ada kemungkinan besar usaha itu akan berkembang dan sebaliknya. Penelitian ini fokus pada UMKM peternakan kambing sebagai usaha utamanya dan dipadukan dengan segala seluk beluk mengenai kambing baik itu makanan kambing, kulit kambing, daging kambing dan kotoran kambing, ada bukti di lapangan bahwa usaha terpadu UMKM mampu bertahan dari permasalahan yang selalu dialami oleh UMKM. Penelitian Rajani dan Sarada (2008) menunjukkan adanya pengaruh yang kuat antara kepemimpinan stratejik terhadap kinerja UMKM, namun Hankinson (2000) menunjukkan adanya pengaruh yang lemah. Hadjimanolis (2000) menunjukkan adanya pengaruh yang kuat antara karakteristik UMKM terhadap kinerja UMKM, namun Ayyagari et al., (2003) menunjukkan adanya pengaruh yang lemah, sehingga perlu dilakukan penelitian lanjutan.

\section{KAJIAN PUSTAKA}

Litratur penelitian tentang kepemimpinan sudah banyak dilakukan namun pembahasan terbatas pada permasalahan umum dalam lingkup perusahaan besar seperti kepemimpinan transformasional (Burns, Bass, \& Handbook, 2008), kepemimpinan transaksional (Salter, Harris, \& McCormack, 2014), laize faire (Salter et al., 2014), para peneliti menutup mata melihat hal hal yang terjadi sekitar lingkungannya padahal dari hal kecil itu kepemimpinan itu dapat mengubah sesuatu yang lebih besar, peneliti terpaku pada teori yang sudah mapan tentang sosok seorang pmimpin padahal bagi banyak orang, pemimpin tidak lahir, tapi dibuat. Akan semakin diterima, bagaimanapun untuk menjadi pemimpin yang baik, seseorang harus memiliki pengalaman, pengetahuan, komitmen, kesabaran, dan yang terpenting keterampilan untuk bernegosiasi dan bekerja denganyang lain untuk mencapai tujuan. Kepemimpinan yang baik dikembangkan melalui proses belajar mandiri, pendidikan, pelatihan, dan akumulasi pengalaman yang relevan (Bass \& Bass, 2008). Menurut Boulding (1956) dalam buku "The Image: Knowledge in Life and Society", menggariskan teori pengetahuan transdisipliner umum tentang pengetahuan dan perilaku manusia, sosial, dan organisasi. Dia menyatakan bahwa dasar Kepemimpinan yang baik adalah karakter yang kuat dan pengabdian tanpa pamrih (Jenkins, 2013).

Ada banyak pandangan kepemimpinan yang berbeda karena ada karakteristik yang membedakan pemimpin dari non-pemimpin. Sementara kebanyakan penelitian saat ini telah beralih dari teori tradisional atau teori berbasis kepribadian ke teori situasi, yang menentukan bahwa situasi di mana kepemimpinan dilaksanakan ditentukan oleh keterampilan dankarakteristikkepemimpinan pemimpin (Avolio, Walumbwa, \& Weber, 2009) , semua teori kontemporer dapat berada di bawah salah satu dari tiga perspektif berikut: kepemimpinan sebagai proses atau hubungan, kepemimpinan sebagai kombinasi ciri atau karakteristik kepribadian, atau kepemimpinan sebagai perilaku tertentu atau, karena lebih sering disebut, keterampilan kepemimpinan. Dalam teori kepemimpinan yang lebih dominan, ada anggapan bahwa, setidaknya sampai tingkat tertentu, kepemimpinan adalah proses yang melibatkan pengaruhnya dengan sekelompok orang menuju realisasi tujuan (Wolinski, 2010).

Teori situasional mengemukakan bahwa para pemimpin memilih tindakan terbaik berdasarkan kondisi situasional atau keadaan (Amanchukwu, Stanley, \& Ololube, 2015). Gaya kepemimpinan yang berbeda mungkin lebih tepat untuk berbagai jenis 
pengambilan keputusan. Misalnya, dalam situasi di mana pemimpin diharapkan menjadi anggota kelompok yang paling berpengetahuan dan berpengalaman, gaya kepemimpinan otoriter mungkin paling tepat (Amanchukwu et al, 2015). Dalam kasus lain di mana anggota kelompok adalah ahli yang ahli dan berharap diperlakukan demikian, gaya demokratis mungkin lebih efektif (Amanchukwu et al, 2015). Situasi yang melibatkan tingkat ketepatan, keahlian teknis, kendala waktu, khususnya di lingkungan yang intensif secara teknologi, kita lebih memilih kepemimpinan transaksional, sedangkan di lingkungan yang sangat intensif, fokus pada mempengaruhi pengikut melalui motivasi dan menghormati emosinya berdasarkan basis Tujuan umum, kepercayaan dan nilai, pilihan yang lebih baik adalah gaya kepemimpinan transformasional (MacGregor Bums, 2003).

Kepemimpinan UMKM terpadu lebih mengedepankan gaya kepemimpinan situasional sebab situasi lingkungan yang sangat dinamis terus mengikuti perkembangan zaman, tidak adanya struktur organisasi, modal yang kurang, menanggung seluruh resiko sehingga hanya dengan mengandalkan pengalaman dan pengetahuan pemilik usaha sekaligus menjadi pemimpin dari usaha itu akan berkembang, Penelitian Rajani dan Sarada (2008) menunjukkan adanya pengaruh yang kuat antara kepemimpinan terhadap kinerja UMKM.

\section{Methode Penelitian}

Para peneliti menggunakan pendekatan longitudinal untuk mengetahui secara pasti perkembangan suatu obyek, survey untuk mengumpulkan data dari sampel penelitian. Penelitian ini menggunakan desain longitudinal di mana teknik kualitatif dan kuantitatif digunakan. Iongitudinal dipilih karena lingkungan dan responden dekat dengan peneliti sehingga penelitian dapat dilakukan secara inten dan mengetahui dengan jelas segala sesuatu perubahan yang terjadi pada responden. Pendekatan ini memungkinkan para peneliti untuk berkonsentrasi pada obyek yang diteliti, sehingga menawarkan solusi untuk setiap bisnis yang mungkin ingin menggunakan temuan yang dinyatakan untuk memperbaiki situasi nyata. Peneliti merasa mungkin untuk memberikan penilaian dan pendapat mereka sendiri karena mereka benar-benar berinteraksi dengan peserta yang diteliti.

Penelitian ini menggunakan sampel 30 pemilik dan pemimpin UMKM dari populasi 60 pemilik dan pemimpin. Tiga puluh karyawan terdiri dari 20 pemilik dan pemimpin UMKM dan 10 pemimpin UMKM yang digunakan sebagai ukuran sampel. Ukuran sampel terdiri dari 18 peternak kambing, 7 peternak sapi, 5 peternak kerbau. Ukuran sampel ini representatif yang memberikan cerminan sejati dari temuan penelitian. Peneliti menggunakan teknik sampling random purpose sampling, Proses pengumpulan datanya menggunakan cohort studi, sample berasal dari semua pemilik dan pemimpin usaha peternakan yang berada di wilayah eks karisidenan Pekalongan, memiliki usaha minimal lima tahun, memiliki ternak minimal sepuluh ekor, usia ternak minimal lima bulan, kandang ternak minimal $4 \times 4 \mathrm{~m}$.

Pemimpin tidak lahir, tapi dibuat. Tetapi, bagaimanapun untuk menjadi pemimpin yang baik, seseorang harus memiliki pengalaman, pengetahuan, komitmen, kesabaran, dan yang terpenting keterampilan untuk bernegosiasi dan bekerja denganyang lain untuk mencapai tujuan. Kepemimpinan yang baik dikembangkan melalui proses belajar mandiri, pendidikan, pelatihan, dan akumulasi pengalaman yang relevan (Bass \& Bass, 2008). pengalaman yang relevan untuk usaha peternakan kuncinya ada dua yaitu pemilihan bibit unggul dan perawatan sehingga dengan modal dua itu mampu untuk mengembangkan usaha yang terkait dengan ternak sehingga kepemimpinan UMKM terpadu akan terus berkembang didukung oleh situasi di mana kepemimpinan dilaksanakan ditentukan oleh keterampilan 
dan karakteristik kepemimpinan pemimpin (Avolio, Walumbwa, \& Weber, 2009).

\section{HASIL DAN PEMBAHASAN}

Hampir $90 \%$ pelaku UKM mulai usahanya by accident bukan by design (Umkm, Bri, \& Purwodadi, 2011). Hasil produk UMKM menjadi kendala sebab produksi berdasarkan kemampuan pelaku UMKM bukan berdasarkan pasar sehingga jaringan pemasaran mengalami hambatan. Produksi UMKM hanya berdasarkan atas kemampuan pelaku, belajar dari pengalaman otodidak, ikut bekerja dengan orang lain ataupun belajar trial error atas suatu usaha.

Data 4.1 Populasi pendidikan peternak menunjukan bahwa sebagaian besar peternak didominasi oleh lulusan sekolah dasar (SD), Tegal 7 orang, Brebes 11 dan Slawi 15, untuk pendidikan Sekolah Menengah Pertama (SMP) Tegal 9, Brebes 7 dan Slawi 3, yang terakhir untuk pendidikan Sekolah Menengah Atas (SMA) Tegal 4, Brebes 2 dan Slawi 2, hal ini menunjukan bahwa pendidikan peternak dari polpulasi sebesar 60 orang pendidikan SD mendominasi, dari ketiga wilayah orang ( $32 \%$ ) dan SMA sebanyak 8 orang (13\%), dari pendidikan SD Slawi berjumalah terbanyak 15 orang.

Tabel 4.2 Sample Jumlah Peternak yang beternak kambing untuk wilayah Tegal berjumlah 4 orang, Brebes 6 orang dan Slawi 8 orang, beternak sapi untuk wilayah Tegal sebanyak 2 orang, Brebes 1 orang dan Slawi 4 orang, yang terakhir beternak Kerbau untuk Tegal tidak ada, Brebes sebanyak satu orang, Slawi empat orang. Data menunjukan bahwa peternak dari ketiga wilayah lebih menyukai ternak kambing dengan alasan perawatan yang mudah, tidak memerlukan landang yang besar dan modal yang kecil. Daerah Slawi menjadi daerah terbanyak untuk peternak kambing.

\section{Pengalaman}

Pembelajaran organisasional terjadi dalam konteks (Glynn et al. 1994) yang mencakup organisasi dan lingkungan di mana organisasi tertanam. Pengalaman adalah apa yang terjadi dalam organisasi ketika melakukan tugasnya (Argote \& Mironspektor, 2011). Pengalaman berinteraksi

Tabel 4.1 : Populasi Pendidikan Peternak

\begin{tabular}{|c|c|c|c|}
\hline \multirow{2}{*}{ Daerah } & \multicolumn{3}{|c|}{ Pendidikan } \\
\hline & Sd & Smp & Sma \\
\hline Tegal & 7 & 9 & 4 \\
\hline Brebes & 11 & 7 & 2 \\
\hline Slawi & 15 & 3 & 2 \\
\hline \multicolumn{4}{|c|}{ Sumber data ; hasil survei lapangan } \\
\hline \multicolumn{4}{|c|}{ Tabel 4.2 : Sample Jumlah Peternak } \\
\hline \multirow[b]{2}{*}{ Daerah } & \multicolumn{3}{|c|}{ Ternak } \\
\hline & Kambing & Sapi & Kerbau \\
\hline Tegal & 4 & 2 & 0 \\
\hline Brebes & 6 & 1 & 1 \\
\hline Slawi & 8 & 4 & 4 \\
\hline
\end{tabular}

Sumber data : Hasil survei Lapangan

sebesar 33 orang (55\%), SMP sebesar 19 dengan konteks untuk menciptakan 
pengetahuan.

Konteks lingkungan mencakup unsurunsur di luar batas organisasi seperti pesaing, klien, lembaga, dan regulator. Ini dapat bervariasi sepanjang banyak dimensi, seperti volatilitas, ketidakpastian, keterkaitan, dan kemurahan hati (Argote \& Miron-spektor, 2011). Konteks lingkungan mempengaruhi pengalaman yang diperoleh organisasi. Sebagai contoh, pesanan untuk produk atau permintaan untuk layanan memasuki organisasi dari lingkungan. Konteks organisasi mencakup karakteristik organisasi, seperti struktur, budaya, teknologi, identitas, ingatan, sasaran, insentif, dan strategi. Konteksnya juga mencakup hubungan dengan organisasi lain melalui aliansi, usaha patungan, dan kemampuan mereka untuk bertindak. Anggota dan alat melakukan tugas: mereka melakukan banyak hal. Sebaliknya, konteks laten tidak mampu bertindak.

Dalam kontek penelitian ini organisasi adalah tempat kerja pelaku UMKM sebelumnya, baik itu diperusahaan resmi maupun tidak resmi seperti ikut bekerja pada orang ataupun yayasan selama bertahun - tahun dengan perbandingan anatara upah dan pekerjaan yang sangat tidak layak namun bagi pelaku UMKM pengalaman bekerja di tempat itu sangat berguna, Pengalaman dapat diperoleh pada tugas-tugas yang telah dilakukan berulangulang di masa lalu (Katila dan Ahuja 2002, Maret 1991, Rosenkopf dan McGrath 2011). Pelaku UMKM menyadari bahwa pendidikan

Tabel 4.3 : Pemilik Ternak dan Pemimpin Usaha Ternak

\begin{tabular}{cccc}
\hline & \multicolumn{3}{c}{ Ternak } \\
\cline { 2 - 4 } Daerah & Kambing & Sapi & Kerbau \\
\hline Tegal & 1 & 2 & 0 \\
Brebes & 4 & 1 & 4 \\
Slawi & 5 & 2 & \\
\hline
\end{tabular}

Sumber data : Hasil survei lapangan

keanggotaan dalam asosiasi.

Konteks berinteraksi dengan pengalaman untuk menciptakan pengetahuan. Secara konseptual, kami mengusulkan membedakan konteks organisasi ke dalam konteks aktif di mana pembelajaran terjadi dan konteks laten yang mempengaruhi konteks aktif (Argote \& Miron-spektor, 2011). Konteks aktif mencakup elemen dasar organisasi, anggota dan alat, yang berinteraksi dengan tugas organisasi. Konteks laten mempengaruhi individu mana yang menjadi anggota organisasi, alat apa yang mereka miliki, dan tugas apa yang mereka lakukan. Di sini, tugas adalah tugas subtugas yang dilakukan untuk melengkapi tugas keseluruhan organisasi. Perbedaan antara konteks aktif dan laten adalah formal mereka tidak terlalu tinggi sehingga mereka harus belajar pengalaman dari mereka yang sudah lama menggeluti bidang itu sebab pengalaman adalah "guru" yang baik (Marck 2010), sehingga mereka rela bekerja dengan upah yang tidak seberapa demi untuk pengalaman yang berharga.

Bukti empiris menyebutkan bahwa urutan atau rutinitas tugas juga dapat berupa repositori pengetahuan dan berfungsi sebagai mekanisme transfer pengetahuan (Darr et al. 1995). Secara tidak sadar pelaku UMKM memiliki pengetahuan dalam bentuk pengalaman selama bertahun tahun yang diulang ulang, pengalaman itu menjadikan dirinya berani mengambil sikap dan tindakan untuk mandiri memelihara ternak.

Keterangan : Pemilik Ternak dan 
Pemimpin Usaha Ternak adalah pelaku UMKM yang memiliki ternak dan usahanya diurus sendiri dengan menejemen sendiri.

\section{Komitmen}

Berbagai pengalaman yang didapat dari mengikuti bekerja dengan orang lain selama bertahun tahun kemudian berani mandiri membuaka usaha sendiri menjadikan pelaku UMKM tahan terhadap permasalahan peternakan, banyak resiko yang harus ditanggunnya, dengan komitmen yang kuat untuk berani usaha sendiri menjadikan pengalaman itu sebagai pengalaman langsung dan tidak langsung berhubungan positif satu sama lain secara komplementer (Bresman 2010). Dan tidak sekalipun ada pemikiran bahwa pengalaman langsung dan pengalaman tidak langsung berhubungan negatif (Wong 2004, Haas dan Hansen 2004, Schwab 2007); yaitu, satu bentuk pengalaman tampaknya menggantikan yang lain. Dalam artian apabila ada pengalaman yang pahit akan berganti usaha yang lain.

Bukti di lapangan pelaku UMKM dan sekaligus menjadi pemimpin dalam usaha UMKM berdasarkan pengalaman autodidak (Argote \& Miron-spektor, 2011) berpikir secara kreatif mengatasi masalah masalah yang timbul dari usahanya dan setiap permasalahan terpecahkan menimbulkan usaha baru secara terpadu. Misal : permasalahan limbah kotoran ternak menjadi permasalahan utama di lingkungan maka mereka berpikir bagaimana menjadikan kotoran tidak hanya bermanfaat namun juga mendatangkat keuntungan secara financial, solusi yang didapatkan adalah dengan cara kotoran itu dikeringkan kemudian digiling dijadikan pupuk. Pupuk menjadi permasalahan baru sebab tidak mudah menjual pupuk kotoran ternak sebab kalah bersaing dengan pupuk buatan pabrik maka solusi yang didapat adalah pelaku UMKM juga menanam rumput dan tebu sehingga ada dua usaha baru dari yang ditimbulkan oleh limbah yaitu, pertama limbah sebagai pupuk untuk memupuk rumput sebagai pakan ternak dan kedua limbah sebagai pupuk tanaman tebu. Ternak kambing selain dijual dalam kondisi hidup pelaku UMKM juga menjadikan dagingnya sebagi sate yang mampu perhari memotong kambing pada hari biasa sebanyak 15 ekor dan pada saat hari besar sebanyak 50 ekor per hari.

\section{Simpulan \\ Kepemimpinan UMKM terpadu adalah sifat seorang pelaku UMKM yang berdasarkan atas pengalaman nya bekerja pada orang lain selama bertahun tahun sehingga berani membuka usaha secara mandiri dengan komitmen yang kuat maka mampu mengembangkan usaha itu menjadi usaha yang dipadukan dari hulu ke hilir dengan konsep terpadu.}




\section{DAFTAR PUSTAKA}

Alan Hankinson: "The key faktors in the profiles of small firm owner managers that influence business performance. The South Coast Small Firms Survey, 1997-2000. "Industrial and Commercial Training, Vol 32 No 3-2000

(Dalkir, 2005)Amanchukwu, R. N., Stanley, G. J., \& Ololube, N. P. (2015). A Review of Leadership Theories, Principles and Styles and Their Relevance to Educational Management. Management, 5(1), 6-14. https://doi.org/10.5923/j.mm.20150501.02

Argote, L., \& Miron-spektor, E. (2011). Organizational Learning : From Experience to Knowledge, 22(5), 1123-1137.

Burns, J. M., Bass, B. M., \& Handbook, T. B. (2008). Transformational leadership, 1-5.

Crăciun, L., Năstase, M., Stamule, T., \& Vizitiu, C. (2015). Leadership in Romanian small to medium enterprises. Sustainability (Switzerland), 7(4), 4183-4198. https://doi. org/10.3390/su7044183

Dalkir, K. (2005). Knowledge Management in Theory and Practice. ButterworthHeinemann (Vol. 4). https://doi.org/10.1002/asi.21613

Salter, C. R., Harris, M. H., \& McCormack, J. (2014). Bass \& Avolio â $€^{\mathrm{TM}}$ s Full Range Leadership Model and Moral Development. E-Leader Milan, (2008), 28.

Umkm, D. A. N. K., Bri, P. T. B., \& Purwodadi, T. K. (2011). MENINGKATKAN KINERJA UMKM NASABAH, 20(2), 64-86.

(Crăc pengetahuan iun, Năstase, Stamule, \& Vizitiu, 2015). Amanchukwu, R. N., Stanley, G. J., \& Ololube, N. P. (2015). A Review of Leadership Theories, Principles and Styles and Their Relevance to Educational Management. Management, 5(1), 6-14. https://doi. org/10.5923/j.mm.20150501.02

Argote, L., \& Miron-spektor, E. (2011). Organizational Learning : From Experience to Knowledge, 22(5), 1123-1137.

Burns, J. M., Bass, B. M., \& Handbook, T. B. (2008). Transformational leadership, 1-5.

Crăciun, L., Năstase, M., Stamule, T., \& Vizitiu, C. (2015). Leadership in Romanian small to medium enterprises. Sustainability (Switzerland), 7(4), 4183-4198. https://doi. org/10.3390/su7044183

Dalkir, K. (2005). Knowledge Management in Theory and Practice. ButterworthHeinemann (Vol. 4). https://doi.org/10.1002/asi.21613

Salter, C. R., Harris, M. H., \& McCormack, J. (2014). Bass \& Avolio â $€^{\mathrm{TM}}$ s Full Range Leadership Model and Moral Development. E-Leader Milan, (2008), 28.

Umkm, D. A. N. K., Bri, P. T. B., \& Purwodadi, T. K. (2011). MENINGKATKAN KINERJA UMKM NASABAH, 20(2), 64-86.

(Burns, Bass, \& Handbook, 2008)Amanchukwu, R. N., Stanley, G. J., \& Ololube, N. P. (2015). A Review of Leadership Theories, Principles and Styles and Their Relevance to Educational Management. Management, 5(1), 6-14. https://doi.org/10.5923/j.mm.20150501.02

Argote, L., \& Miron-spektor, E. (2011). Organizational Learning : From Experience to Knowledge, 22(5), 1123-1137.

Burns, J. M., Bass, B. M., \& Handbook, T. B. (2008). Transformational leadership, 1-5.

Crăciun, L., Năstase, M., Stamule, T., \& Vizitiu, C. (2015). Leadership in Romanian small to medium enterprises. Sustainability (Switzerland), 7(4), 4183-4198. https://doi. org/10.3390/su7044183

Dalkir, K. (2005). Knowledge Management in Theory and Practice. ButterworthHeinemann (Vol. 4). https://doi.org/10.1002/asi.21613

Salter, C. R., Harris, M. H., \& McCormack, J. (2014). Bass \& Avolio â€ $€^{\mathrm{TM}}$ s Full Range Leadership 
Model and Moral Development. E-Leader Milan, (2008), 28.

Umkm, D. A. N. K., Bri, P. T. B., \& Purwodadi, T. K. (2011). MENINGKATKAN KINERJA UMKM NASABAH, 20(2), 64-86.

(Salter, Harris, \& McCormack, 2014)Amanchukwu, R. N., Stanley, G. J., \& Ololube, N. P. (2015). A Review of Leadership Theories, Principles and Styles and Their Relevance to Educational Management. Management, 5(1), 6-14. https://doi.org/10.5923/j.mm.20150501.02

Argote, L., \& Miron-spektor, E. (2011). Organizational Learning : From Experience to Knowledge, 22(5), 1123-1137.

Burns, J. M., Bass, B. M., \& Handbook, T. B. (2008). Transformational leadership, 1-5.

Crăciun, L., Năstase, M., Stamule, T., \& Vizitiu, C. (2015). Leadership in Romanian small to medium enterprises. Sustainability (Switzerland), 7(4), 4183-4198. https://doi. org/10.3390/su7044183

Dalkir, K. (2005). Knowledge Management in Theory and Practice. ButterworthHeinemann (Vol. 4). https://doi.org/10.1002/asi.21613

Salter, C. R., Harris, M. H., \& McCormack, J. (2014). Bass \& Avolio â $€^{\mathrm{TM}}$ s Full Range Leadership Model and Moral Development. E-Leader Milan, (2008), 28.

Umkm, D. A. N. K., Bri, P. T. B., \& Purwodadi, T. K. (2011). MENINGKATKAN KINERJA UMKM NASABAH, 20(2), 64-86.

(Salter et al., 2014)Amanchukwu, R. N., Stanley, G. J., \& Ololube, N. P. (2015). A Review of Leadership Theories, Principles and Styles and Their Relevance to Educational Management. Management, 5(1), 6-14. https://doi.org/10.5923/j.mm.20150501.02

Argote, L., \& Miron-spektor, E. (2011). Organizational Learning : From Experience to Knowledge, 22(5), 1123-1137.

Burns, J. M., Bass, B. M., \& Handbook, T. B. (2008). Transformational leadership, 1-5.

Crăciun, L., Năstase, M., Stamule, T., \& Vizitiu, C. (2015). Leadership in Romanian small to medium enterprises. Sustainability (Switzerland), 7(4), 4183-4198. https://doi. org/10.3390/su7044183

Dalkir, K. (2005). Knowledge Management in Theory and Practice. ButterworthHeinemann (Vol. 4). https://doi.org/10.1002/asi.21613

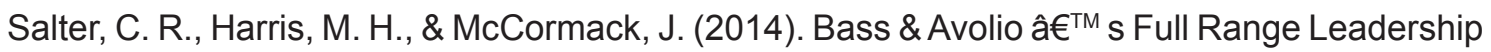
Model and Moral Development. E-Leader Milan, (2008), 28.

Umkm, D. A. N. K., Bri, P. T. B., \& Purwodadi, T. K. (2011). MENINGKATKAN KINERJA UMKM NASABAH, 20(2), 64-86.

(Amanchukwu, Stanley, \& Ololube, 2015)Amanchukwu, R. N., Stanley, G. J., \& Ololube, N. P. (2015). A Review of Leadership Theories, Principles and Styles and Their Relevance to Educational Management. Management, 5(1), 6-14. https://doi.org/10.5923/j. $\mathrm{mm} .20150501 .02$

Argote, L., \& Miron-spektor, E. (2011). Organizational Learning : From Experience to Knowledge, 22(5), 1123-1137.

Burns, J. M., Bass, B. M., \& Handbook, T. B. (2008). Transformational leadership, 1-5.

Crăciun, L., Năstase, M., Stamule, T., \& Vizitiu, C. (2015). Leadership in Romanian small to medium enterprises. Sustainability (Switzerland), 7(4), 4183-4198. https://doi. org/10.3390/su7044183

Dalkir, K. (2005). Knowledge Management in Theory and Practice. ButterworthHeinemann (Vol. 4). https://doi.org/10.1002/asi.21613

Salter, C. R., Harris, M. H., \& McCormack, J. (2014). Bass \& Avolio â€ $€^{\mathrm{TM}}$ s Full Range Leadership Model and Moral Development. E-Leader Milan, (2008), 28.

Umkm, D. A. N. K., Bri, P. T. B., \& Purwodadi, T. K. (2011). MENINGKATKAN KINERJA UMKM 
NASABAH, 20(2), 64-86.

(Umkm, Bri, \& Purwodadi, 2011).Amanchukwu, R. N., Stanley, G. J., \& Ololube, N. P. (2015). A Review of Leadership Theories, Principles and Styles and Their Relevance to Educational Management. Management, 5(1), 6-14. https://doi.org/10.5923/j.mm.20150501.02

Argote, L., \& Miron-spektor, E. (2011). Organizational Learning : From Experience to Knowledge, 22(5), 1123-1137.

Burns, J. M., Bass, B. M., \& Handbook, T. B. (2008). Transformational leadership, 1-5.

Crăciun, L., Năstase, M., Stamule, T., \& Vizitiu, C. (2015). Leadership in Romanian small to medium enterprises. Sustainability (Switzerland), 7(4), 4183-4198. https://doi. org/10.3390/su7044183

Dalkir, K. (2005). Knowledge Management in Theory and Practice. ButterworthHeinemann (Vol. 4). https://doi.org/10.1002/asi.21613

Salter, C. R., Harris, M. H., \& McCormack, J. (2014). Bass \& Avolio â€ $€^{\mathrm{TM}}$ s Full Range Leadership Model and Moral Development. E-Leader Milan, (2008), 28.

Umkm, D. A. N. K., Bri, P. T. B., \& Purwodadi, T. K. (2011). MENINGKATKAN KINERJA UMKM NASABAH, 20(2), 64-86.

(Argote \& Miron-spektor, 2011).Amanchukwu, R. N., Stanley, G. J., \& Ololube, N. P. (2015). A Review of Leadership Theories, Principles and Styles and Their Relevance to Educational Management. Management, 5(1), 6-14. https://doi.org/10.5923/j.mm.20150501.02

Argote, L., \& Miron-spektor, E. (2011). Organizational Learning : From Experience to Knowledge, 22(5), 1123-1137.

Burns, J. M., Bass, B. M., \& Handbook, T. B. (2008). Transformational leadership, 1-5.

Crăciun, L., Năstase, M., Stamule, T., \& Vizitiu, C. (2015). Leadership in Romanian small to medium enterprises. Sustainability (Switzerland), 7(4), 4183-4198. https://doi. org/10.3390/su7044183

Dalkir, K. (2005). Knowledge Management in Theory and Practice. ButterworthHeinemann (Vol. 4). https://doi.org/10.1002/asi.21613

Salter, C. R., Harris, M. H., \& McCormack, J. (2014). Bass \& Avolio â€ $€^{\mathrm{TM}}$ s Full Range Leadership Model and Moral Development. E-Leader Milan, (2008), 28.

Umkm, D. A. N. K., Bri, P. T. B., \& Purwodadi, T. K. (2011). MENINGKATKAN KINERJA UMKM NASABAH, 20(2), 64-86.

http://www.kabarbisnis.com/read/2845011

https://peluangusaha.kontan.co.id/news/ini-6-masalah-utama-ukm-sulit-tumbuh 